\title{
Speciation measurements of airborne mercury species in northern Finland; Evidence for long range transport of air masses depleted in mercury
}

\author{
M. Nerentorp ${ }^{1},{ }^{2}$, K. Kyllonen ${ }^{2}$, I. Wängberg ${ }^{3}$ and P. Kuronen ${ }^{2}$ \\ ${ }^{1}$ Department of environmental inorganic chemistry, Chemical and Biological Engineering, Chalmers University of \\ Technology, Kemivägen 4, 41296 Göteborg, Sweden, michelle.nerentorp@chalmers.se \\ ${ }^{2}$ Air Quality Laboratories, Finnish Meteorological Institute, P.O. Box 503, FIN-00101 Helsinki, Finland, \\ katriina.kyllonen@fmi.fi,pirjo.kuronen@fmi.fi \\ ${ }^{3}$ IVL Swedish Environmental Institute, Aschebergsgatan 44, 41133 Göteborg, ingvar.wangberg@ivl.se
}

\begin{abstract}
Mercury speciation measurements were performed at the Arctic measurement site, Pallas Matorova, in northern Finland during the period 12-04-02 to 12-04-26. For the first time $\mathrm{Hg}$ speciation measurements with high sensitivity and temporal resolution were performed at this site. The measurement allowed simultaneous determination of TGM, GEM, GOM and particulate bound mercury. Evidence for long range transport of air masses depleted in mercury is provided as well as a study of possible mercury sources determining the temporal variations in airborne mercury species at the site.
\end{abstract}

Key words: Mercury, TGM, GEM, GOM, PBM, AMDE

\section{Introduction}

Mercury in the atmosphere originates from natural as well as anthropogenic sources. Burning of fossil fuels for energy production constitutes the most important anthropogenic mercury source.

In air, $\mathrm{Hg}$ can be in the gaseous elemental form (GEM), as gaseous oxidized mercury (GOM) or as particulate bound mercury (PBM) (AMAP, 2011). Mercury in air is predominantly in its elemental form and due to that it is relatively inert, it can be transported long distances before being oxidised and deposited to land and sea surfaces. The atmospheric residence time of GEM is estimated to be about one half to one year during most conditions.

In contrast during Atmospheric mercury depletion events (AMDEs), that occur in Arctic and Antarctic regions during springtime, GEM may entirely be oxidised within hours or days in processes involving halogen radical photo-chemistry (Schroeder et al., 1998; Lindberg et al., 2002; Sommar et al., 2007). Ozone is simultaneously depleted by $\mathrm{Br}$ radicals in a reaction yielding $\mathrm{BrO}$ and $\mathrm{O}_{2}$. Hence, $\mathrm{BrO}$ can be used as a tracer for areas where depletion of mercury and ozone occur. $\mathrm{Br}$ radicals are also likely to be involved in initiating the oxidation of GEM which through further oxidation steps lead to formation of GOM (AMAP, 2011). During AMDEs, all or part of the elemental mercury is transferred to GOM and particulate bound mercury. The source of bromine is sea salt and emission of bromine occur from freshly formed sea ice surfaces.

GMOS (Global Mercury Observation System) is a five year long EU project aiming to establish a global observation system for $\mathrm{Hg}$ in air and water (GMOSGlobal Mercury Observation System, 2012). The Pallas Matorova station, in northern Finland is one of the land based measurement sites within GMOS.

Total gaseous mercury (TGM) and total particulate mercury (TPM) have been measured at the PallasMatorova station using manual methods since 1996 (Munthe et al., 2007). From these measurements daily TGM and weekly TPM values are obtained showing that both TGM and TPM generally are low. During 2002 to 2011 an average TGM concentration of $1.41 \mathrm{ng} \mathrm{m}^{-3}$ was obtained. The corresponding TPM value is $2.0 \mathrm{pg} \mathrm{m}^{-3}$. Both parameters show a temporal variation indicating that the concentration of airborne mercury at this Arctic site is controlled by long range transport.

Here we present the result from a 3 week long measurement campaign at which the mercury species/fractions, TGM, GEM, $\mathrm{PBM}_{2.5}$ and GOM were measured with high sensitivity and temporal resolution. The temporal variation in mercury concentrations was investigated in terms of backward trajectories and ancillary data.

\section{Materials and Methods}


The Pallas-Matorova station is managed by the Finnish Meteorological Institute (FMI) and is located in a natural park, far away from potential pollution sources as industries and traffic. The measurements are performed near the lake Pallasjärvi at the Matorova hill $\left(68^{\circ} 00^{\prime} \mathrm{N}\right.$, $\left.24^{\circ} 14^{\prime} \mathrm{E}\right), 340 \mathrm{~m}$ above the sea level. The station area consists of an open field surrounded by a coniferous forest.

A Tekran 1130/35-system was used to determine the airborne $\mathrm{Hg}$ fractions, GEM, $\mathrm{PBM}_{2.5}$ and GOM (Lindberg et al., 2002). For comparison, a Tekran 2537A was used to measure TGM concentrations. GEM and TGM were measured with a detection limit of better than $0.1 \mathrm{ng} \mathrm{m}^{-3}$. The detection limits obtained in the measurements of particulate mercury and GOM were 1.3 and $1.6 \mathrm{pg} \mathrm{m}^{-3}$, respectively, at $4 \mathrm{~h}$ temporal resolution.

$\mathrm{O}_{3}$-concentrations where monitored with a Thermo Scientific $\mathrm{O}_{3}$-analyzer, model $49 \mathrm{i}$.

The NOAA hybrid single-partice lagrangian integrated trajectory model was used to calculate backward trajectories. The calculations were made interactively using the GDAS meterological data sets. This model facility is available on the Web (http://ready.arl.noaa.gov/HYSPLIT.php).

The GOME-2/ SCIAMACHY DOAS nadir data browser from the University of Bremen (IUP DOAS) was used to detect elevated BrO-concentrations in the northern hemisphere. The data browser is available online (http://www.doasbremen.de/scia_data_browser.htm?gas= bro\&view $=$ nh\&instr $=$ gome 2 ).

\section{Results and Discussion}

Results from the mercury speciation measurements are shown in Figure 1. The concentrations are low in respect to GEM and very low in respect to GOM and particulate mercury. All GEM and TGM values obtained are well above the detection limit for these species. The average particulate mercury concentration is $2.2 \mathrm{pg} \mathrm{m}^{-3}$, which is higher than the detection limit, $1.3 \mathrm{pg} \mathrm{m}^{-3}$, obtained in this study. On the other hand is the average GOM concentration, $1.5 \mathrm{pg} \mathrm{m}^{-3}$, slightly below the detection limit, which was determined to be $1.6 \mathrm{pg} \mathrm{m}^{-3}$. However, the GOM and particulate mercury values forming distinct peaks are $2-3$ times higher than the detection limits and were used in the further evaluation. The GEM and TGM data sets are similar with exactly the same temporal variation. Hence, the TGM data could be used to verify the GEM measurement.

A covariation between GEM and ozone was observed during the $4^{\text {th }}$ to $11^{\text {th }}$ of April as is shown in Figure 2. This is an indication of mercury depletion events often occurring during spring time in Arctic areas (Schroeder et al., 1998; Steffen et al., 2002; Lindberg et al., 2002; Sommar et al., 2007). However, mercury depletion is not likely to be a local phenomenon in the Pallas area.

Backward trajectories calculated for this period show several occasions with air masses of Arctic Oceanic origin entering to the Pallas Matorova site.

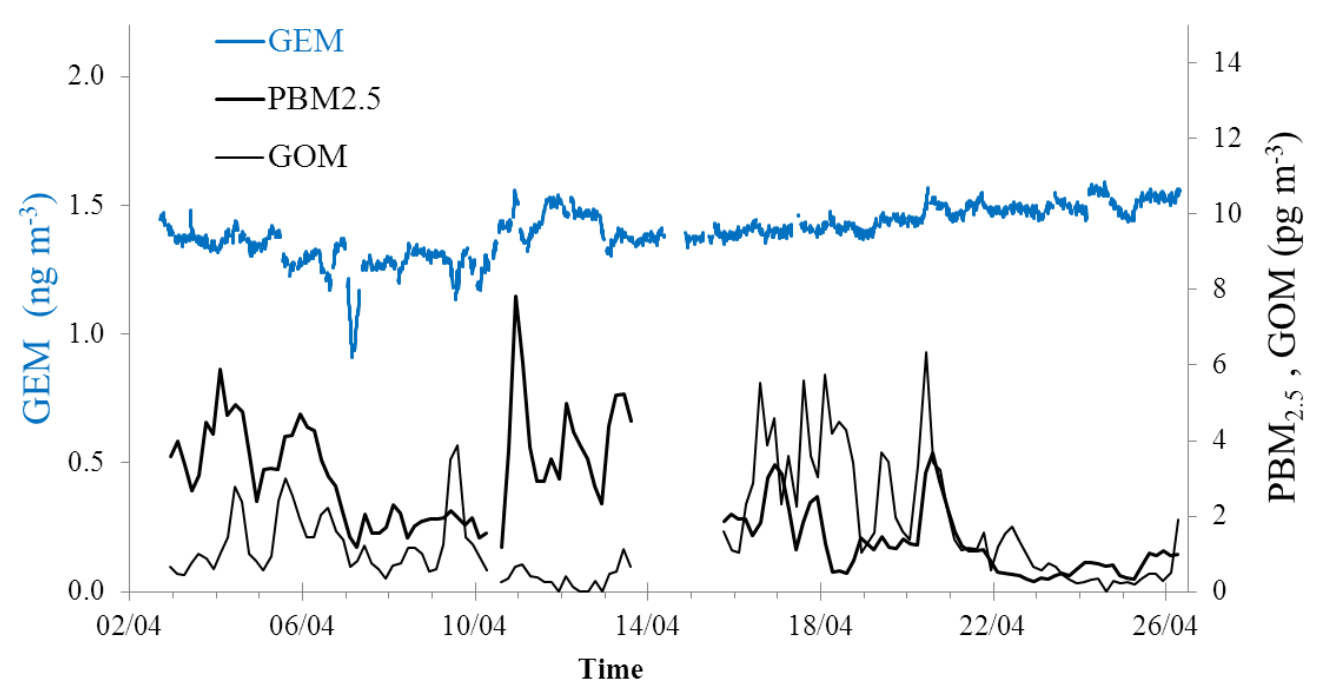

Fig. 1. Time series of GEM, PBM and GOM measured at Pallas Matorova during the period $2^{\text {nd }}$ to $26^{\text {th }}$ of April 2012. $\mathrm{PBM}$ and GOM were measured with a time resolution of $4 \mathrm{~h}$.

The most noticeable event occurred the $7^{\text {th }}$ of April, see Figure 2, where the GEM concentration rapidly dropped from $1.4 \mathrm{ng} \mathrm{m}^{-3}$ to $0.9 \mathrm{ng} \mathrm{m}^{-3}$. Simultaneously the ozone concentration decreased from $44 \mu \mathrm{g} \mathrm{m}^{-3}$ to 29 $\mu \mathrm{g} \mathrm{m}{ }^{-3}$.

Backward trajectories calculated for this event, see Figure 3, show that the air masses entering to Pallas originated from sea ice areas of the northern coast of Greenland and the west coast of Svalbard.
$\mathrm{BrO}$ in the troposphere can be used as a tracer for AMDEs (Lindberg et al., 2002; Sommar et al., 2007). Figure 4 shows the distribution of $\mathrm{BrO}$ clouds in the Arctic Ocean during three days in April, 2012. BrO clouds are formed in the area between Northern Greenland and Svalbard and west of Svalbard at the 4th of April, as shown in Figure 4. The BrO column density reaches a maximum on the 5 th of May. Hence, the 


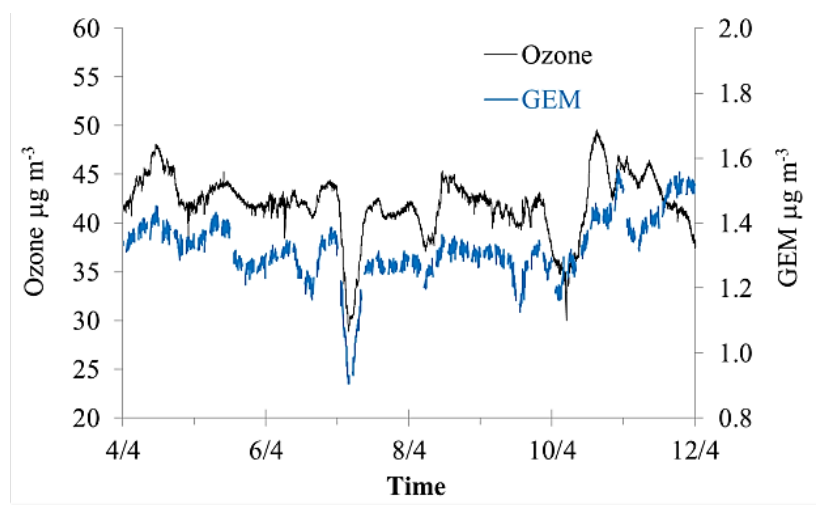

Fig. 2. GEM and $\mathrm{O}_{3}$ concentrations during April 4 - 12, 2012.

trajectory plots in Figure 3 show that the origin of the air masses reaching Pallas the $7^{\text {th }}$ of April are areas where mercury and ozone depletion are likely to occur. This means that the effect of mercury depletion events that occurred in the Arctic Ocean about $2000 \mathrm{~km}$ away could be traced at the Pallas measurement site $48 \mathrm{~h}$ later. Indications of this kind are not entirely new. Similar signatures from TGM measurements have earlier been reported from both Pallas and Andøya, on the Norwegian north coast (Wängberg et al., 2010).

That mercury depletion events can be traced at places very distant from the mercury depletion event itself gives a hint on the geographical scale of this phenomenon. However, the present data also indicates that the environmental impact of long distant transport of air masses depleted in mercury may be very low.

As shown Figure 1 is the dip in GEM not accompanied with increased concentrations of particulate mercury or GOM, as normally is the case (Sommar et al., 2007). The reason for this is probably that all the oxidized mercury has been removed from the air via deposition etc. during the transport. At the $9^{\text {th }}$ of April, however, a small dip in GEM is actually accompanied with significant concentrations of GOM and particulate mercury. Trajectories calculated for this occasion shows that air masses reaching Pallas are coming from the Arctic Ocean, but could not be connected to elevated BrO concentrations.

Several of the small peaks in particulate mercury and GOM have been examined by help of backward trajectories. The result indicates that the peaks are associated with air masses from south and north as well as air coming from the east, i.e., the Kola Peninsula. Trajectories that passed over the city Monchegorsk, 360 $\mathrm{km}$, east of Pallas, which is known for nickel and copper production, may explain some of the GOM peaks.

Some other occasions with slightly elevated concentrations in particulate mercury and GOM may be due to air transport from mining areas and smelters in Sweden. Though, it must be stated that this is only indications, nothing certain can be said about specific

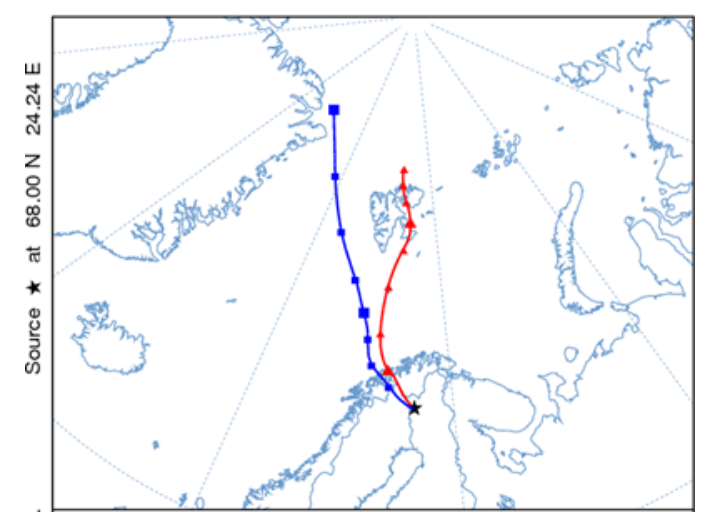

Fig. 3. Two trajectories, of $48 \mathrm{~h}$ lengths, calculated using the NOAA HYSPLIT Model. Left, backward trajectory ending at Pallas 00:00 UTC the 7th of April. Right, backward trajectory ending at Pallas 06:00 UTC the 7th of April.

sources based on the present data. The highest peak in particulate mercury, $9.2 \mathrm{pg} \mathrm{m}^{-3}$ was obtained $22: 30$ the $10^{\text {th }}$ of April and is associated with air from the Baltic States arriving to the site directly from the south. Hence, the source of the slightly enhanced concentration of particulate mercury is likely be caused by human activities in the Baltic States and in Finland.

\section{Conclusion}

Evidence for long range transport of air masses depleted in mercury has been found during a three week long campaign at the Pallas Matorova measurement site. The signatures in GEM and ozone were not accompanied by elevated concentrations of particulate mercury and GOM. Hence, the environmental impact of AMDEs in the Pallas area is likely to be low.

The concentration of oxidized airborne mercury is generally low in the Pallas area, but show dynamic temporal fluctuations which to the most part is likely to be due to long range transport but may also partly be influenced by nearby sources.

\section{Acknowledgements}

The measurement campaign at Pallas was supported by the European Commission through the GMOS project, Grant agreement no: 265113.

Andreas Richter is greatly acknowledged for his help with BrO maps.

\section{References}

AMAP, 2011. AMAP Assessment 2011: Mercury in the Arctic. Arctic Monitoring and Assessment Program (AMAP), Oslo, Norway. xiv+193 pp.GMOSGlobal Mercury Observation System. Available at (www.gmos.eu).

Lindberg S E, Brooks S, Lin C J, Scott K J, Landis M S, 


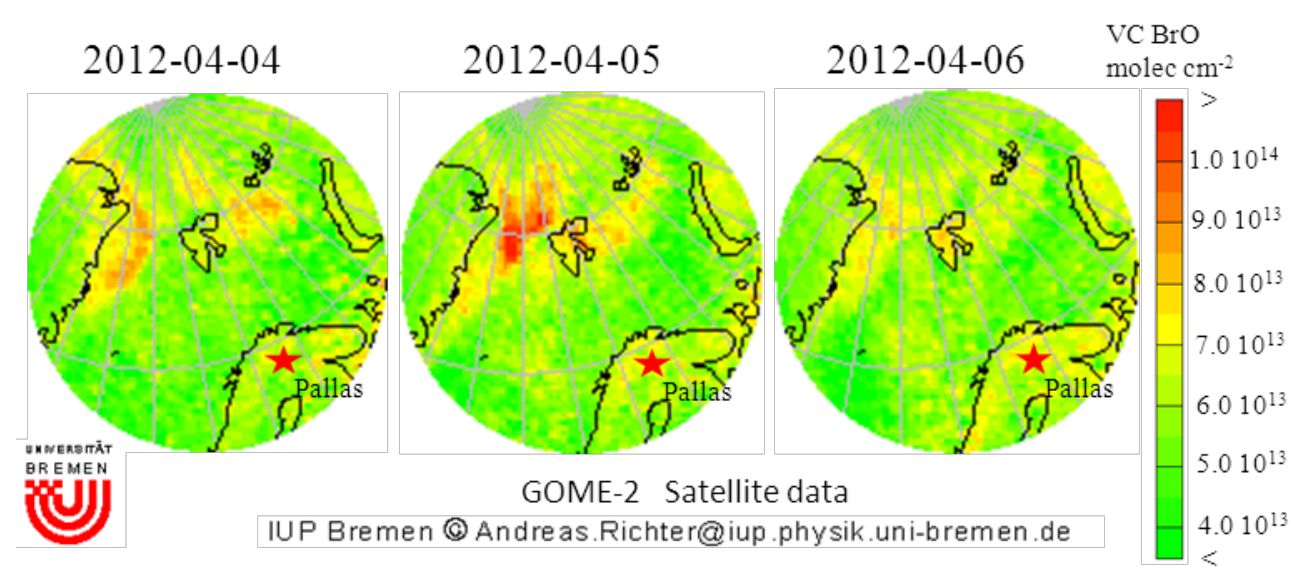

Fig. 4. BrO maps showing the distribution of $\mathrm{BrO}$ in the Arctic Ocean.

Stevens R K, Goodsite M, Ritcher A. Dynamic oxidation of gaseous mercury in the Arctic troposphere at polat

sunrise. Environmental Science and Technology 2002; 36:1245-1256.

Munthe J, Wängberg I, Rognerud S, Fjeld E, Verta M, Porvari P, Meili M. Mercury in Nordic ecosystems. IVL Report B 1761:2007. (http://www3.ivl.se/rapporter/pdf /B1761.pdf)

Schroeder W H, Anlauf K G, Barrie L A, Lu J Y, Steffen A, Schneeberger D R, Berg T. Arctic springtime depletion of mercury. Nature 1998; 394:331-332.

Sommar J, Wangberg I, Berg T, Gardfeldt K, Munthe J, Richter A, Urba F, Wittrock F, Schroeder W H.
Circumpolar transport and air-surface exchange of atmospheric mercury at Ny-Alesung (79 degrees N), Svalbard, spring 2002. Atmospheric Chemistry and Physics 2007; 7:151-166.

Steffen A, Schroeder W H, Bottenheim J, Narayana J, Fuentes J D. Atmospheric mercury concentrations: measurements and profiles near snow and ice surfaces in the Canadian Arctic during Alert 2000. Atmospheric Environment 2002; 36 (2002): 26532661.

Wängberg I, Aspmo Pfaffhuber K, Berg T, Hakola H, Kyllönen K, Munthe J, Porvari P, Verta M. Atmospheric and catchment mercury concentrations and fluxes in Fennoscandia. Tema Nord 2010: 594. 